\title{
Coupling of Neuronal Nitric Oxide Synthase to NMDA Receptors via Postsynaptic Density-95 Depends on Estrogen and Contributes to the Central Control of Adult Female Reproduction
}

\author{
Xavier d'Anglemont de Tassigny, ${ }^{1,2}$ Céline Campagne, ${ }^{1,2}$ Bénédicte Dehouck, ${ }^{1,2}$ Danièle Leroy, ${ }^{1,2}$ Gay R. Holstein, ${ }^{3}$ \\ Jean-Claude Beauvillain, ${ }^{1,2}$ Valérie Buée-Scherrer, ${ }^{1,2}$ and Vincent Prevot ${ }^{1,2}$ \\ ${ }^{1}$ Inserm, Jean-Pierre Aubert Research Centre, U837, Development and Plasticity of the Postnatal Brain, 59045 Lille cedex, France, ${ }^{2}$ University of Lille 2 , \\ School of Medicine, Institut de Médecine Prédictive et de Recherche Thérapeutique, 59046 Lille cedex, France, and ${ }^{3}$ Department of Neurology, Mount Sinai \\ School of Medicine, New York, New York 10029
}

\begin{abstract}
Considerable research has been devoted to the understanding of how nitric oxide (NO) influences brain function. Few studies, however, have addressed how its production is physiologically regulated. Here, we report that protein-protein interactions between neuronal NO synthase (nNOS) and glutamate NMDA receptors via the scaffolding protein postsynaptic density-95 (PSD-95) in the hypothalamic preoptic region of adult female rats is sensitive to cyclic estrogen fluctuation. Coimmunoprecipitation experiments were used to assess the physical association between nNOS and NMDA receptor NR2B subunit in the preoptic region of the hypothalamus. We found that nNOS strongly interacts with NR2B at the onset of the preovulatory surge at proestrus (when estrogen levels are highest) compared with basal-stage diestrous rats. Consistently, estrogen treatment of gonadectomized female rats also increases nNOS/NR2B complex formation. Moreover, endogenous fluctuations in estrogen levels during the estrous cycle coincide with changes in the physical association of nNOS to PSD-95 and the magnitude of NO release in the preoptic region. Finally, temporary and local in vivo suppression of PSD-95 synthesis by using antisense oligodeoxynucleotides leads to inhibition of nNOS activity in the preoptic region and disrupted estrous cyclicity, a process requiring coordinated activation of neurons containing gonadotropin-releasing hormone (the neuropeptide controlling reproductive function). In conclusion, our findings identify a novel steroid-mediated molecular mechanism that enables the adult mammalian brain to control NO release under physiological conditions.
\end{abstract}

Key words: neuronal nitric oxide synthase; glutamate; sex steroids; estrous cycle; LHRH; hypothalamus

\section{Introduction}

Nitric oxide (NO) and its downstream signaling cascades are critical to various cellular functions in the brain such as apoptosis, differentiation, development, synaptic plasticity, and neurosecretion (Boehning and Snyder, 2003; McCann et al., 2003). NO, which travels readily across cellular membranes and enters presynaptic sites, is capable of coordinating neuronal inputs in a restricted brain volume delimited by its half-life and diffusion constant (Prast and Philippu, 2001). Because NO cannot be stored in synaptic vesicles, as are other neurotransmitters, mech-

Received Nov. 29, 2005; revised April 19, 2007; accepted April 19, 2007.

This work was supported by Inserm Grants U816 and U837, the Fondation pour le Recherche Médicale (Equipe FRM), I'Agence Nationale de la Recherche, the Université de Lille 2, and the Imaging Core of IFR114. X.d.d.T. and C.C. were PhD students supported by a fellowship from INSERM and the Région Nord Pas de Calais. We thank Dr. P. C. Emson (Medical Research Council, Laboratory for Molecular Research, Cambridge, UK) for his generous supply of antibodies against nNOS. We are grateful to Sergio R. 0jeda, Marie-Pierre Junier, and Sebastien G. Bouret for their valuable comments on this manuscript.

Correspondence should be addressed to Dr. Vincent Prevot, Inserm U837, Bâtiment Biserte, Place de Verdun, 59045 Lille Cedex, France. E-mail : prevot@ille.inserm.fr.

D01:10.1523/JNEUROSCI.5595-06.2007

Copyright $\odot 2007$ Society for Neuroscience $\quad$ 0270-6474/07/276103-12\$15.00/0 anisms that regulate its synthesis with respect to time and space are crucial in determining its biological effects. Hence, precise regulation of NO synthase (NOS) activity during fluctuating physiological conditions may be critical to normal brain function as well as the avoidance of neuronal damage or death. Accordingly, there are several endogenous mechanisms modulating neuronal NOS (nNOS) (Boehning and Snyder, 2003), which likely constitutes the predominant source of $\mathrm{NO}$ in neurons (Bredt and Snyder, 1990) and concentrates inside postsynaptic dendritic spines (Burette et al., 2002). One mechanism for the regulation of nNOS activity may reside in the differential coupling of this $\mathrm{Ca}^{2+}$-activated enzyme to glutamate NMDA receptor channels by the scaffolding protein postsynaptic density-95 (PSD-95), which acts as an adaptor protein, thereby physically and functionally coupling NMDA receptors to nNOS (Christopherson et al., 1999; Sattler et al., 1999; Aarts et al., 2002).

Estrogens have profound effects on brain structure and physiology (Maggi et al., 2004; Simerly, 2005). In particular, they have been shown to play a key role in the cyclic increases in dendritic spine density and synaptogenesis in the rat hippocampus throughout the estrous cycle (Woolley and McEwen, 1992). Like- 
wise, estrogen treatment in gonadectomized female rats controls dynamic changes in spine density in the hippocampus (Gould et al., 1990) and hypothalamus (Calizo and Flanagan-Cato, 2000). These findings raise the possibility that, in addition to neuronal connectivity remodeling, the short-term variations in circulating levels of estrogens that occur during the reproductive cycle may result in ongoing, cyclic fluctuation in protein-protein interactions at the postsynaptic density, thereby constituting a potential mechanism for their control of NO production within the brain (Weiner et al., 1994; Pu et al., 1996).

Using the preoptic region of the hypothalamus (central to reproductive control) as a model system, we investigated whether endogenous estrogen regulates the state of activation of nNOS through changes in NMDA receptor/PSD-95/nNOS association and whether cyclic variations in the estrogen levels of the region during the estrous cycle suffice to modulate this ternary complex assembly. In addition, we determined the magnitude of NO release in preoptic region explants obtained from adult female rats with low (diestrus) or high (proestrus) endogenous estrogen levels. Finally, we investigated whether local suppression of PSD-95 expression in the preoptic region in vivo impacts hypothalamic function. Our results indicate that cyclic changes in female sex hormones are indeed associated with marked variations in the activity of a major brain neuronal signaling pathway and in a model system that is critical to species survival.

\section{Materials and Methods \\ Animals}

Sprague Dawley female rats (Janvier, Saint-Berthevin, France) weighing 250-300 g were used for NO-production measurements, immunoprecipitation, Western blots from tissue explants, immunohistofluorescence, and intracerebral infusion experiments. Animals were housed in a room with controlled photoperiods ( $14 \mathrm{~h}$ of light and $10 \mathrm{~h}$ of darkness) and temperature $\left(21-23^{\circ} \mathrm{C}\right)$ with food and water ad libitum. Rats were fed under a regular chow diet that contained trace amounts of phytoestrogen (2016; Harlan France, Gannat, France) (Odum et al., 2001). Vaginal smears were examined daily, and only rats that exhibited at least two consecutive $4 \mathrm{~d}$ estrous cycles were used for experiments. Diestrus I and II were defined by a predominance of leukocytes in the vaginal lavage, the day of proestrus was characterized by the predominance of nucleated rounded epithelial cells, and the day of estrus was distinctly characterized by large numbers of clustered cornified squamous epithelial cells. For primary cell culture from the hypothalamic preoptic region, an entire litter of Sprague Dawley rats born the day of the culture setup [postnatal day 0 (P0)] were used. All experiments were performed in accordance with the European Communities Council Directive of November 24, 1986 (86/609/EEC), regarding mammalian research.

\section{Amperometric measurements of NO release from preoptic region explants}

Female rats were decapitated at diestrus II $16 \mathrm{~h}$ (Di16h) or at proestrus $16 \mathrm{~h}$ (Pro16h); after rapid removal of the brain, the meninges and optic chiasm were discarded, and the preoptic region was isolated under a binocular magnifying glass with Wecker's scissors (Moria, Antony, France). The external limits for this dissection were as follows: lateral, the external border of the medial preoptic area (MPO); dorsal, the internal border of anterior commissures; the anteroposterior limits were +0.95 to $-0.51 \mathrm{~mm}$ from bregma, according to the Swanson (1996) atlas. The total dissection time was $<3 \mathrm{~min}$ from decapitation. After dissection, explants were washed twice in modified Krebs'-Ringer's bicarbonate/ glucose buffer, $\mathrm{pH} 7.4$, in an atmosphere of $95 \% \mathrm{O}_{2}-5 \% \mathrm{CO}_{2}$ and immersed in microfuge tubes containing $800 \mu \mathrm{l}$ of the same medium. Each tube contained one single preoptic explant. Spontaneous NO release was measured directly using an NO-specific amperometric probe (ISO-NOP; World Precision Instruments, Sarasota, FL) as described previously (Prevot et al., 1999; Knauf et al., 2001). Calibration of the electrochemical sensor was performed before each experiment according to the manu- facturer's instructions using various concentrations of a nitrosothiol donor, $S$-nitroso- $N$-acetyl-D,L-penicillamine (Sigma, Saint-Quentin Fallavier, France). The concentration of NO gas in solution was measured in real time, at a sampling rate of six per second (Prevot et al., 1999), using a computer-interfaced DUO-18 (World Precision Instruments) for data acquisition. The experimental values were transferred to SigmaPlot and SigmaStat (Jandel, San Raphael, CA) for graphic representation and evaluation. Before NO-efflux measurements, a baseline was obtained by monitoring the basal amperometric activity of the probe when immersed in Krebs'-Ringer's bicarbonate/glucose buffer at $35^{\circ} \mathrm{C}$ for $30 \mathrm{~min}$ in the absence of tissue. The sensor used to monitor $\mathrm{NO}$ was then placed in an explant-containing tube $1 \mathrm{~mm}$ above the tissue surface using a micromanipulator (Carl Zeiss-Eppendorf, Hambourg, Germany). Preoptic region explants were then submitted to five $30 \mathrm{~min}$ incubation periods at $35^{\circ} \mathrm{C}$, including a $1 \mathrm{~h}$ recovery period and a $90 \mathrm{~min}$ data acquisition phase. At the end of each $30 \mathrm{~min}$ period, $600 \mu \mathrm{l}$ of medium was removed and replaced with $600 \mu \mathrm{l}$ of fresh prewarmed oxygenated Krebs'-Ringer's bicarbonate/glucose buffer as detailed previously (Knauf et al., 2001; Bouret et al., 2002a). In experiments to test the specificity of the response monitored by the amperometric probe, the NOS inhibitor $\mathrm{N}$-acetyl-Lmethyl ester (L-NAME; Calbiochem, Meudon, France) was used at $1 \mathrm{~mm}$. A drop in NO flux reflects a shallower gradient, stemming from diminished production at the source.

\section{Assay of NOS activity}

NOS activity was determined by measuring the formation of nitrite produced in samples during a timed reaction using the BIOXYTECH nitric oxide synthase assay kit (OXIS International, Portland, OR). Experiments were performed on equal amounts of protein from preoptic region homogenates processed according to the manufacturer's instructions. Spectrophotometric quantitation of nitrite was performed at $540 \mathrm{~nm}$ using Greiss reagents.

\section{Primary neuron-containing cultures from the preoptic region}

Primary cultures were prepared from newborn (P0) Sprague Dawley rats. After decapitation and removal of the brain, the preoptic region was dissected as described previously and placed in ice-cold DMEM (Invitrogen, Carlsbad, CA). Each explant was cut into five to six smaller pieces and incubated for $1 \mathrm{~h}$ at $37^{\circ} \mathrm{C}$ and a $5 \% \mathrm{CO}_{2}$ atmosphere in DMEM containing papain $(33 \mathrm{U} / \mathrm{ml}, 3126$; Worthington-Cooper, Lakewood, NJ), deoxyribonuclease I (DNase I; $125 \mathrm{U} / \mathrm{ml}, \mathrm{D} 4527$; Sigma), and L-cysteine (2.5 mM; Sigma) for papain activation. Papain-incubated tissues were washed twice in DMEM with the trypsin inhibitor ovomucoid (1.54 mg/ml, 109878; Roche Diagnostics, Somerville, NJ), DNase I (125 $\mathrm{U} / \mathrm{ml}$, Sigma), and bovine serum albumin $(0.62 \mathrm{mg} / \mathrm{ml}$, A7906; Sigma) to end the enzymatic reaction. The fragments were crushed through a 20 $\mu \mathrm{m}$ nylon mesh (Sefar America, Kansas City, MO), and the dissociated cells were centrifuged at $90 \times g$ for $10 \mathrm{~min}$ and resuspended in serum-free neuronal-defined medium consisting of Neurobasal-A medium without phenol red (12340-015; Invitrogen) with 2\% (v/v) B-27 supplement (17504-044; Invitrogen), 1\% (v/v) Glutamax (35050-038; Invitrogen), and $2 \%(\mathrm{v} / \mathrm{v})$ antibiotics (penicillin/streptomycin, 10378-016; Invitrogen). Cells were counted with a hemacytometer (Thoma Cell, Marienfield, Germany). For estradiol treatments, $2 \times 10^{6}$ cells were plated in 10-cm-diameter poly-L-lysine (molecular weight, >300,000; P5899; Sigma)-coated dishes (Falcon). For oligodeoxynucleotide (ODN) treatments, $1 \times 10^{6}$ cells per well were seeded into poly-L-lysine-coated sixwell plates (Falcon). Primary cell cultures used for immunofluorescence experiments were plated onto 12 -mm-diameter poly-L-lysine-coated coverslips in 24-well plates (Falcon) with a density of $7 \times 10^{5}$ cells per well. Primary cultures were maintained in an incubator at $37^{\circ} \mathrm{C}$ and $5 \%$ $\mathrm{CO}_{2}$ for 10-12 d in vitro (DIV; time of plating, 0 DIV), and their medium was changed after $2 \mathrm{~d}$ of culture and subsequently three times per week.

\section{Antibodies}

Antibodies used for coimmunoprecipitation and Western blot experiments. Rabbit polyclonal anti-nNOS antibody (sc-8309; 1:500 for immunoblotting and $1 \mu \mathrm{g} / 750 \mu \mathrm{l}$ for immunoprecipitation), rabbit polyclonal antiendothelial NOS (eNOS) antibody (sc-654; 1:500 for immunoblotting and $1 \mu \mathrm{g} / 750 \mu \mathrm{l}$ for immunoprecipitation), and the goat polyclonal an- 
tibody used for immunoblotting of actin (sc-1616; 1:1000 for immunoblotting) were obtained from Santa Cruz Biotechnology (Santa Cruz, CA). Monoclonal anti-PSD-95 antibodies used for immunoprecipitation (MA1-045 and MA1-046; $2 \mu \mathrm{g} / 750 \mu \mathrm{l}$ ) and immunoblotting (MA1046; $1: 500)$ were purchased from Affinity BioReagents (Golden, CO). The specificity of both antibodies (clone 6G6-1C9 and clone 7E3-1B8, respectively) was described by Kornau et al. (1995). The well characterized rabbit antibody used for immunoprecipitation $(2 \mu \mathrm{g} / 750 \mu \mathrm{l})$ and immunoblotting (1:250) of NR2B (71-8600) was obtained from Zymed (San Francisco, CA) (Christopherson et al., 1999). Secondary antibodies used for Western blot detection [anti-mouse (1:5000), anti-rabbit (1: $10,000)$, and anti-goat/sheep (1:20,000) peroxidase conjugate (HRP)] were from Sigma.

Antibodies used for immunohistofluorescence. Sheep polyclonal antinNOS (1:3000) was a generous gift from Dr. P. C. Emson (Medical Research Council, Laboratory for Molecular Research, Cambridge, UK) (Herbison et al., 1996). Rabbit polyclonal anti-nNOS (61-700; 1:250) and anti-NR2B (71-8600; 1:500) were purchased from Zymed, described by Christopherson et al. (1999), and previously characterized for immunocytochemistry by others (El-Husseini et al., 2000; Burette et al., 2002; Czaja et al., 2006). Monoclonal anti-PSD-95 (MA1-045; 1:400) was purchased from Affinity BioReagents. The specificity of this antibody was described by Kornau et al. (1995). Rabbit polyclonal anti-gonadotropinreleasing hormone (GnRH; 1:2000) was a generous gift from Prof. G. Tramu (Centre National de la Recherche Scientifique, URA 339, Université Bordeaux I, Talence, France) (Beauvillain and Tramu, 1980). Mouse anti-citrulline monoclonal antibodies (1:30) were produced and characterized by G. R. Holstein as described previously (Martinelli et al., 2002). Secondary donkey anti-rabbit Alexa Fluor 568 conjugate (A-21099; 1:500) used for nNOS and GnRH detection and streptavidin Alexa Fluor 488 conjugate (S-11223; 1:500) used for NR2B detection were purchased from Invitrogen (Eugene, OR). Secondary goat anti-rabbit biotin conjugate (BA-1000; 1:500) used for NR2B detection was obtained from Vector Laboratories (Burlingame, CA).

\section{Protein extraction and coimmunoprecipitation}

Protein extraction and coimmunoprecipitation from tissue explants. Preoptic region explants were obtained from cycling female rats (Di16h and Pro16h) as described above. After dissection, each fragment was placed in a microcentrifuge tube, snap frozen in liquid nitrogen, and stored at $-80^{\circ} \mathrm{C}$. Protein extracts of four preoptic region samples were prepared in $750 \mu$ l of lysis buffer ( $\mathrm{pH} 7.4,25 \mathrm{~mm}$ Tris, $50 \mathrm{~mm} \beta$-glycerophosphate, 1.5 mм EGTA, 0.5 mм EDTA, 1 mм sodium pyrophosphate, $1 \mathrm{~mm}$ sodium orthovanadate, $10 \mu \mathrm{g} / \mathrm{ml}$ leupeptin and pepstatin, $10 \mu \mathrm{g} / \mathrm{ml}$ aprotinin, $100 \mu \mathrm{g} / \mathrm{ml}$ PMSF, and $1 \%$ Triton X-100) by trituration of the fragments through 22 and 26 gauge needles in succession. The tissue lysates were cleared by centrifugation at $12,000 \times g$ for $15 \mathrm{~min}$, and $30 \mu \mathrm{l}$ of protein A-Sepharose beads (1:1 slurry in lysis buffer, P3391; Sigma) were added to supernatants to remove endogenous G-type Igs. After 30 min of gentle rocking at $4^{\circ} \mathrm{C}$, beads were centrifuged $(15 \mathrm{~s}, 12,000 \times g)$, and supernatants were collected. Protein content was determined using the Bradford method (Bio-Rad, Hercules, CA). Equal amounts of protein $(2.2 \mathrm{mg}$; four rats were required to obtain this quantity of protein) in a total volume of $750 \mu \mathrm{l}$ of lysis buffer were incubated with gentle rocking at $4^{\circ} \mathrm{C}$ for $2 \mathrm{~h}$ with $1 \mu \mathrm{g}$ of rabbit polyclonal IgG anti-nNOS or $2 \mu \mathrm{g}$ of the other antibodies used for immunoprecipitation in this study (anti-NR2B, antiPSD-95 MA1-045, anti-PSD-95 MA1-046, or anti-phospho-nNOSSer1412). Thereafter, $60 \mu \mathrm{l}$ of protein A-Sepharose beads in lysis buffer (1:1 blend) was added to each sample and incubated for 1 additional hour with gentle rocking at $4^{\circ} \mathrm{C}$. The Sepharose beads were pelleted by brief centrifugation, the supernatant was collected, and $375 \mu$ l of $3 \times$ sample buffer (187 mm Tris-Base, 9\% SDS, 15\% glycerol, $15 \%$ $\beta$-mercaptoethanol, and bromophenol blue, $\mathrm{pH} 6.8$ in $1 \times$ final) was added to it for analysis of nonimmunoprecipitated proteins. The beads were washed three times with ice-cold lysis buffer and boiled for $5 \mathrm{~min}$ in $50 \mu \mathrm{l}$ of $2 \times$ sample buffer. When necessary, the samples were stored at $-80^{\circ} \mathrm{C}$ until use.

Protein extraction and coimmunoprecipitation from cell culture. Cells in six-well plates were collected in $350 \mu \mathrm{l}$ of lysis buffer, and two wells were pooled for ODN-treated cell coimmunoprecipitation experiments. The coimmunoprecipitation procedure was identical to the one detailed above for tissue explants, except that antibodies were incubated overnight and protein A-Sepharose beads were incubated for $3 \mathrm{~h}$.

\section{Western blotting analysis}

Samples were reboiled for $5 \mathrm{~min}$ after thawing and electrophoresed for 75 $\mathrm{min}$ at $150 \mathrm{~V}$ in $7 \%$ Tris-acetate, or for $50 \mathrm{~min}$ at $200 \mathrm{~V}$ in $4-12 \% \mathrm{MES}$ precast SDS-polyacrylamide gels according to the protocol supplied with the NuPAGE system (Invitrogen). After size fractionation, the proteins were transferred onto polyvinylidene difluoride $0.2 \mu \mathrm{m}$ pore-size membranes (LC2002; Invitrogen) in the blot module of the NuPAGE sytem (Invitrogen) for $75 \mathrm{~min}$ at room temperature (RT). Blots were blocked for $1 \mathrm{~h}$ in TBS with $0.05 \%$ Tween 20 (TBST) and 5\% nonfat milk at RT, reacted overnight at $4^{\circ} \mathrm{C}$ with their respective primary antibody, and washed four times with TBST before being exposed to HRP-conjugated secondary antibodies diluted in 5\% nonfat milk TBST for $1 \mathrm{~h}$ at RT. The immunoreactions were detected with enhanced chemiluminescence (NEL101; PerkinElmer, Boston, MA). When stripping and reprobing were required, the membranes were incubated in a stripping solution (62.5 mm Tris-HCl, 2\% SDS, pH 6.7, and $100 \mathrm{~mm} \beta$-mercaptoethanol) for $30 \mathrm{~min}$ with gentle rocking at $65^{\circ} \mathrm{C}$. An HRP-conjugated secondary antibody was used to verify that all former immunoreactivity was successfully stripped.

\section{Immunohistofluorescence}

Animals were anesthetized with chloral hydrate (400 mg/kg, i.p.) and perfused transcardially with $5-10 \mathrm{ml}$ of saline, followed by $500 \mathrm{ml}$ of $4 \%$ paraformaldehyde in $0.1 \mathrm{~m}$ phosphate buffer (PB), pH7.4. Brains were removed and immersed in the same fixative for $2 \mathrm{~h}$ at $4^{\circ} \mathrm{C}$ and stored in PB until slicing. Eighty-micrometer Vibratome (VT1000S; Leica, Wetzlar, Germany) coronal floating sections containing the preoptic region were collected in ice-cold $\mathrm{PB}$ and blocked in $\mathrm{PB}$ with 5\% normal donkey serum (D9663; Sigma) and 0.3\% Triton X-100 (Sigma) for $1 \mathrm{~h}$ at RT before incubation with sheep anti-nNOS (1:3000) and rabbit anti-NR2B (1:500) in the same blocking solution overnight at $4^{\circ} \mathrm{C}$. Sections were washed extensively in PB and exposed to secondary antibodies: first with Alexa Fluor 568-conjugated anti-sheep (1:500) and biotinylated antirabbit (1:500) in PB with Triton X-100 for $1 \mathrm{~h}$ at RT and then with Alexa Fluor 488 streptavidin conjugate (1:500) for $1 \mathrm{~h}$. After washes, slices were incubated for 1-2 min with $0.02 \%$ Hoechst 33258 bis-benzimide (H3569; Invitrogen) in PB for nuclear fluorescent staining mounted on glass slides and coverslipped in Permafluor medium (434990; Immunon, Pittsburgh, PA). Control sections were incubated in the absence of a primary antibody.

Double-immunofluorescent labeling images were acquired with a fluorescent system (DMRB microscope, DC300FX camera, FW4000 software; Leica). For illustration purposes, photomontages of the preoptic region were prepared with the help of Photoshop CS2 (Adobe Systems, San Jose, CA) using four to nine digitalized images acquired with a $20 \times$ (numerical aperture 0.5) objective.

Analysis was undertaken as described previously by us (Lemoine et al., 2005) and others (Wintermantel et al., 2006) under the aforementioned fluorescent microscope equipped with appropriate Pleomopak filters. Alexa 488-labeled cells were detected with the L4 filter $(450-490 \mathrm{~nm})$. Alexa 568-labeled neurons were examined with the N2.1 filter (515-560 $\mathrm{nm})$. Identification of double-labeled cells was made by switching one filter cube to the other and also with the B/G/R filter (400/20, 495/15, and $570 / 50 \mathrm{~nm}$ ), which allowed the visualization of both Alexa 488 and Alexa 568. The NR2B-immunoreactive cells displayed a green fluorescence from Alexa 488, and nNOS-immunoreactive neurons displayed a red fluorescence from Alexa 598. Analysis was undertaken by counting the numbers of single immunoreactive cells and dual-labeled neurons in the upper focal plan of each section (one focal plane counted every $80 \mu \mathrm{m}$ ). The distribution and number of dual-labeled cells were counted in the preoptic region represented by plates 17-21 of the Swanson (1996) brain atlas and more precisely in the anteroventral periventricular nucleus (AVPV), the median preoptic nucleus (MEPO), the MPO, and the medial preoptic nucleus (MPN). Cell counts in the AVPV and the MPN 
were determined by placing a square $\left(0.0625 \mathrm{~mm}^{2}\right)$ over the AVPV (plates 17-19) and the MPN (plates 19-21) under a $40 \times$ objective $(0.7$ Plan Fluotar) and counting all immunoreactive cells on five hemisections from each rat. The same procedure was undertaken for the MEPO and the MPO from plates 17-19 and counting the numbers of immunoreactive neurons in 10 hemisections from each rat. Values for each rat were used to determine mean counts, and these were used to generate means \pm SEM values for each group.

\section{$n N O S / L$-citrulline immunostainings and analysis}

Anesthetized rats were perfused transcardially with $500 \mathrm{ml}$ of $4 \%$ paraformaldehyde and $0.3 \%$ glutaraldehyde in PB. Coronal sections were cut at $80 \mu \mathrm{m}$ using a vibratome and processed for immunofluorescence. Sections were rinsed in PBS and reacted with $0.2 \% \mathrm{NaBH}_{4}$ for $45 \mathrm{~min}$ at RT to reduce tissue autofluorescence (Clancy and Cauller, 1998), rinsed again, and preincubated in blocking buffer (PBS containing 5\% normal goat serum and $0.05 \%$ Triton $\mathrm{X}-100$ ) overnight at $4^{\circ} \mathrm{C}$. Primary antibodies (mouse anti-citrulline and rabbit anti-nNOS) diluted in blocking buffer were subsequently added to sections and incubated overnight at $4^{\circ} \mathrm{C}$. After PBS rinses, sections were reacted for $1 \mathrm{~h}$ at RT with biotinylated anti-mouse antibodies diluted in PBS. Tyramide signal amplification was accomplished by placing the sections in an avidin-biotin solution (Vector Laboratories) for $30 \mathrm{~min}$, followed by incubation in a tyramide signal amplification solution (Individual Indirect Tyramide Reagent Pack; PerkinElmer) for 20 min according to the manufacturer's instructions. Deposited biotin was detected with Alexa 488-conjugated streptavidin. For the nNOS staining, sections were then incubated in goat anti-rabbit IgG Alexa 568 for 1 additional hour. Sections were mounted and coverslipped with Permafluor medium. Slides from diestrous $(n=$ $6)$ or proestrous $(n=6)$ rats were numerically coded to obscure the treatment group; L-citrulline- and nNOS-immunoreactive cells were counted manually by using a Leica DMRB microscope. Immunoreactive cells were counted in the upper focal plan of each section (one focal plane counted every $80 \mu \mathrm{m}$ ) through the preoptic region as described above. The mean number of immunopositive cells in each zone of the preoptic region was compared between stages of the estrous cycle.

\section{PSD-95 immunostaining and analysis}

The immunofluorescent protocol used to stain PSD-95 in coronal sections containing the preoptic region was identical to the one described above for L-citrulline. Image analysis was performed using ImageJ analysis software (W. S. Rasband, National Institutes of Health, Bethesda, MD; http://rsb.info.nih.gov/ij/, 1997-2006). Briefly, each image was binarized, so as to isolate labeled structures from background, as well as compensate for differences in fluorescent intensity. The integrated intensity was then calculated for each image, which reflects the sum of the gray values in the selection. This procedure was performed on $445 \times 332 \mu \mathrm{m}$ grayscale images captured at the tip of the injection site with a $20 \times$ objective.

\section{Assessment of estrogen effects on $n N O S-N R 2 B$ coupling}

Twenty-four animals were bilaterally ovariectomized (OVX; day 0) under anesthesia by intraperitoneal injection of $10 \mathrm{mg} / \mathrm{kg}$ xylazine $(2 \%$ Rompun; Bayer, Pittsburgh, PA) and $60 \mathrm{mg} / \mathrm{kg}$ ketamine (Ketalar; ParkeDavis, Courbevoie, France). Animals were divided into two groups: eight animals received only vehicle and were killed at $14 \mathrm{~h}$ on day 17; eight animals received a single subcutaneous injection of estradiol benzoate in sesame oil (S3547; $\mathrm{E}_{2} \mathrm{~B}, 30 \mu \mathrm{g} / \mathrm{rat}, \mathrm{E} 8515$; Sigma) at $10 \mathrm{~h}$ on day 15 and were killed at $14 \mathrm{~h}$ on day 17, as described previously (Bouret et al., 2002b). This estrogen-substitution protocol was suggested previously (Bouret et al., 2002b) to mimic the preovulatory increase in plasma estrogen in our model system (Prevot et al., 1998). Preoptic region explants were collected as described above.

\section{Primary cell culture treatments with ODNs}

Neuronal cultures were treated with 15-nucleotide oligomer phosphorothioated sense or antisense ODNs (MWG Biotech, Roissy, France) corresponding to nucleotides 435-449 of rat PSD-95/SAP90 mRNA (GenBank accession number M96853). Phosphorothioated antisense (5'GAATGGGTCACCTCC- $3^{\prime}$ ) and sense and missense (5'-CCGCTC-
TATCGAGGA-3') ODNs $(5 \mu \mathrm{M})$ were added to the culture medium during feedings at 4, 6, 8, and 10 DIV. At 12 DIV, cultures were rinsed with ice-cold PBS, snap frozen on dry ice, and stored at $-80^{\circ} \mathrm{C}$. ODN sequences exhibited no similarity to any other mammalian genes [BLAST (Basic Local Alignment Search Tool) search (Altschul et al., 1997)] and were previously used by others (Sattler et al., 1999) to block PSD-95 expression in mouse cortical neurons in vitro.

\section{Intracerebral infusion of ODNs}

To determine the importance of PSD-95 expression in the central control of the reproductive cycle, in vivo experiments were performed to reduce the expression of PSD-95 in the preoptic region. The antisense and sense ODNs described above were chronically infused into the preoptic region of cycling female rats $[0.00 \mathrm{~mm}$ anteroposterior and lateral from bregma, $8 \mathrm{~mm}$ depth from the skull (Swanson, 1996)] by a stereotaxically implanted 28 gauge infusion cannula (Plastics One, Roanoke, VA) connected to a subcutaneously implanted mini-osmotic pump (model 1007D; Alzet, Palo Alto, CA). The pump had a flow rate of $0.5 \mu \mathrm{l} / \mathrm{h}$ coupled to a capacity of $100 \mu \mathrm{l}$, resulting in a delivery period of $7 \mathrm{~d}$. Each pump was loaded with sterile $0.9 \% \mathrm{NaCl}$ containing $0.2 \mathrm{nmol} / \mu \mathrm{l}$ antisense or sense, connected to the infusion device and primed overnight at $37^{\circ} \mathrm{C}$. The assembly was implanted into a cycling $230-250 \mathrm{~g}$ female rat (at least two consecutive regular estrous cycles) using a stereotaxic apparatus (David Kopf Instruments, Tujunga, CA) under xylazine/ketamine anesthesia. Her estrous cycle phase and body weight were monitored daily for $15 \mathrm{~d}$ after surgery. To assess the extent of the affected area by the ODNs, three rats were infused with an FITC-conjugated antisense ODN (5'GAATGGGT ${ }^{*}$ CACCTCC- $3^{\prime}$; FITC linked site is noted $T^{*}$ ). FITCconjugated ODN (MWG Biotech)-infused animals were perfused transcardially before the osmotic pump depletion date. Subsequent to the infusion experiment, each rat was killed, and the implantation site of the cannula and extent of infusion solution depletion were assessed. To determine whether ODN administration into the preoptic region actually altered nNOS activity in situ, double immunofluorescence staining for $\mathrm{nNOS}$ and $\mathrm{L}$-citrulline was performed on an additional series of animals centrally infused either with saline, L-NAME ( $5 \mathrm{~mm}$, a NOS inhibitor), or antisense PSD-95. Immunodetection of L-citrulline that is formed enzymatically from L-arginine in equimolar amounts with NO by NOS was indeed shown to identify NO production sites within neurons (Eliasson et al., 1997;Keilhoff et al., 2000;Martinelli et al., 2002). Analysis was performed at the infusion site by counting the numbers of singlelabeled (red fluorescence) and dual-labeled (red and green fluorescences) nNOS neurons. Cell counts were performed within two squares of $0.0625 \mathrm{~mm}^{2}$, each positioned in mirror at the tip of the infusion site and counting all immunoreactive cells in five sections from each rat.

\section{Statistics}

The differences between several groups were analyzed by one-way ANOVA, followed by the Student-Newman-Keuls multiple comparison test for unequal replication. The comparison between two groups was subjected to the unpaired $t$ test. Before statistical analysis, percentages were subjected to arc-sine transformation to convert them from a binomial to a normal distribution (Zar, 1984). Data from animals within the same ODN treatment group were subjected to one-way repeatedmeasures ANOVA, followed by all pairwise multiple comparison procedure using the Student-Newman-Keuls method. The level of significance was set at $p<0.05$.

\section{Results}

\section{Spontaneous NO release from the preoptic region of the} hypothalamus is different at two representative stages of the estrous cycle

To determine the effects of the estrous cycle on NO fluxes in the rat preoptic region directly, amperometric measures were performed with an NO-specific probe on tissue explants dissected from diestrous II and proestrous rats. Baseline currents were recorded in the absence of tissue explants, and the increased currents resulting from amperometric probe exposure to the explants were then measured. As illustrated in Figure $1 A$, the mean 
A $\mathrm{NO}(\mathrm{nM})$

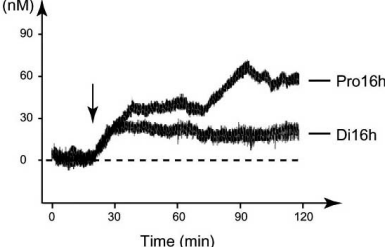

B

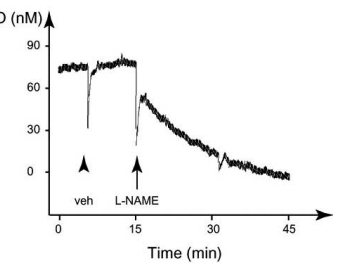

C

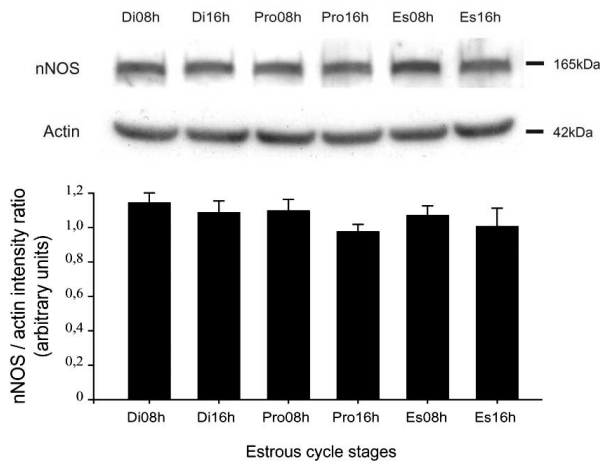

Figure 1. NO effluxes generated by NOS across the estrous cycle. $\boldsymbol{A}$, Representative profiles of spontaneous NO secretion from preoptic region explants at two different stages of the estrous cycle in the female rat. Differential current measured by the self-referencing probe, converted to flux (vertical axis; see Materials and Methods), increased after the addition of single preoptic explants in survival medium at the time indicated by the arrow. Comparisons between stages of the estrous cycle indicated that preoptic explants produced significantly more N0 on the afternoon of proestrus than on the afternoon of diestrus $(p=0.014)$. $\boldsymbol{B}$, Representative response of a proestrous rat preoptic explant to vehicle (veh; arrowhead) or to $1 \mathrm{~mm}$ L-NAME (arrow). Comparisons between treatments indicated that L-NAME, but not vehicle, significantly reduced NO production by the preoptic region during proestrus ( $p=0.017$ ). The transient drops in current on substance application (arrowhead and arrow) are artifacts. C, Absence of changes in nNOS protein expression in the preoptic region of the hypothalamus during the estrous cycle of the adult female rat. Proteins were collected from six different stages of the estrous cycle: diestrus $118 \mathrm{~h}$ (Di08h) and $16 \mathrm{~h}$ (Di16h), proestrus $8 \mathrm{~h}$ (Pro08h) and $16 \mathrm{~h}$ (Pro16h), estrus $8 \mathrm{~h}$ (Es08h) and $16 \mathrm{~h}$ (Es16h). Twenty-five micrograms of protein per lane were electrophoresed and immunoblotted with antibodies to nNOS (top), and membranes were reprobed with antibodies to actin (middle). A representative blot from eight independent experiments is shown. Bottom, The protein levels are expressed in arbitrary densitometric units as the ratio between the nNOS signal and the signal obtained with constitutively expressed actin in each sample. Error bars indicate SEM. There is no statistically significant difference between groups.

amplitude of NO effluxes was significantly higher in proestrus $(47.75 \pm 8.02 \mathrm{nM} ; n=7)$ than in diestrus II $(19.39 \pm 5.77 \mathrm{nM} ;$ test, $p=0.014 ; n=7)$. NO concentrations reached $60-70 \mathrm{nM}$ at proestrus, whereas they rarely exceeded $30 \mathrm{~nm}$ at diestrus. The significant reduction in NO effluxes after adding the NOS inhibitor L-NAME (Fig. $1 B$ ) ( $\Delta$ NO effluxes, $+4.92 \pm 0.91 \mathrm{nM}$ with vehicle vs $-65.75 \pm 13.58 \mathrm{nM}$ with $1 \mathrm{~mm}$ L-NAME; paired $t$ test, $p=0.017 ; n=4$ each) to the survival medium demonstrated that amperometric measurements were selectively monitoring NOSgenerated NO production. Interestingly, the increase in $\mathrm{NO}$ effluxes measured on proestrus via amperometry (Fig. 1 $\mathrm{A}$ ) was paralleled by a significant increase in nNOS intrinsic activity ( $t$ test, $p=0.001 ; \mathrm{Di} 16 \mathrm{~h}, 13.9 \pm 2.8 \mathrm{fmol} / \mathrm{ml} / \mathrm{min}$ vs Pro $16 \mathrm{~h}$, $5.8 \pm 1.3 \mathrm{fmol} / \mathrm{ml} / \mathrm{min} ; n=4$ and $n=5$, respectively) as revealed by in vitro $\mathrm{nNOS}$ catalytic activity measures in preoptic region extracts from diestrous and proestrous rats. Altogether, our results provide direct evidence that NO production fluctuates during the estrous cycle in the preoptic region, which contains some of the most highly expressing nNOS cell populations in the rat brain (Bredt et al., 1991; Herbison et al., 1996).
Estrous cycle has no effect on nNOS protein expression in the adult hypothalamic preoptic region

To ascertain whether changes in hypothalamic expression of nNOS may account for variations in NO effluxes from the preoptic region associated with the female reproductive cycle, as suggested by others (Okamura et al., 1994; Pu et al., 1998), we subjected total preoptic region protein extracts from cycling female rats to Western blot analyses. nNOS was easily detected by immunoblotting (Fig. 1C). Unexpectedly, nNOS expression did not vary across the estrous cycle in the preoptic region (Fig. 1C) ( $n=8$ per estrous cycle stage; one-way ANOVA, $p=0.548$ ), demonstrating that modulation of NO production is not directly linked to changes in nNOS protein synthesis. These data suggest that NO secretory regulation is attributable to changes in hypothalamic neuronal nNOS activity and raise the possibility that posttranslational modifications and/or differential association of the enzyme with stimulatory or inhibitory proteins may play an essential regulatory role for nNOS under physiologically fluctuating conditions.

NMDA receptor NR2B subunit is expressed by NO-producing hypothalamic neurons and is highly physically associated with nNOS at Pro16h

Because nNOS activity is primarily regulated by increases in the local intracellular $\left[\mathrm{Ca}^{2+}\right]$, which activates nNOS through calmodulin binding (Bredt and Snyder, 1990), and because $\mathrm{Ca}^{2+}$ influx through the NMDA receptor but not other $\mathrm{Ca}^{2+}$ influx pathways efficiently promotes NO synthesis (Garthwaite et al., 1988; Bredt and Snyder, 1990), we focused our investigations on NMDA receptor/nNOS association within hypothalamic neurons. Fluorescence microscopy studies showed that virtually all nNOS-expressing neurons of the preoptic region express the NMDA receptor NR2B subunit (Fig. 2), which is known to interact with nNOS (Christopherson et al., 1999; Sattler et al., 1999). Interestingly, the extent of nNOS/NR2B colocalization neither varied during the estrous cycle (Di16h vs Pro16h; $p>0.05 ; n=4$ animals per stage) nor fluctuated among the different zones of the preoptic region considered (Fig. 2). Conversely, additional quantitative analysis showed that the number of NR2B-labeled neurons coexpressing nNOS neither varied among the different zones of the preoptic region nor fluctuated during the estrous cycle (Table 1) ( $p>0.05)$. Our morphological data thus suggest that the number of hypothalamic neurons colocalizing NR2B and nNOS remains constant across the estrous cycle.

Having demonstrated that preoptic nNOS neurons contain NMDA receptors in vivo, we next investigated whether these receptors interact with nNOS by performing coimmunoprecipitation and immunoblot assays. To avoid any bias caused by putative changes in protein expression, we used antibodies at a concentration that precipitates submaximal quantities of the targeted protein (Fig. 3A). Immunoprecipitation with nNOS antibodies, but not with eNOS antibodies (both raised in rabbit), resulted in the coprecipitation of NR2B NMDA subunits (Fig. $3 B$ ). Strikingly, although NR2B protein expression does not vary during the reproductive cycle (Fig. $3 E)(n=4$ per estrous cycle stage; one-way ANOVA, $p=0.51$ ), physical proximity of nNOS with NMDA receptors increases significantly on proestrus compared with diestrus (Fig. 3C) (NR2B/nNOS signal ratio, $0.504 \pm$ 0.039 in Di16h vs $0.840 \pm 0.118$ in Pro16h; $n=5$ independent experiments; $t$ test, $p=0.035$ ). Conversely, immunoprecipitation with NR2B antibodies also results in increased coprecipitation of nNOS in preoptic region protein extracts from proestrous rats compared with diestrous rats (data not shown). These find- 
ings show for the first time that, within neurons, the physical association between NMDA receptors and nNOS varies depending on physiological conditions.

\section{Differential NR2B/nNOS complex} formation involves changes in physical association of PSD-95/nNOS but not NR2B/PSD-95

Recent studies demonstrated that physical coupling of nNOS with NMDA receptors involves the scaffolding protein PSD-95 and the assembly of the ternary complex (Christopherson et al., 1999) required to efficiently couple $\mathrm{Ca}^{2+}$ influx, via NMDA receptors, to NO synthesis and activity (Sattler et al., 1999; Ishii et al., 2006). To investigate whether PSD-95 also acts as a scaffolding protein that links nNOS and NR2B in hypothalamic neurons, we performed immunoprecipitation experiments on solubilized rat preoptic region extracts using an antibody to PSD-95. The presence of NR2B, nNOS, or PSD-95 was sought by immunoblotting. Both nNOS and NR2B coimmunoprecipitated with PSD-95 (Fig. 4). Interestingly, whereas the relative levels of NR2B coprecipitated with PSD-95 remained unchanged over the different stages of the reproductive cycle (Fig. $4 B)(\mathrm{NR} 2 \mathrm{~B} / \mathrm{PSD}-95$ signal ratio, $0.314 \pm$ 0.052 in Dil6h vs $0.304 \pm 0.037$ in Pro16h; $t$ test, $p=0.873 ; n=4$ independent experiments), the levels of $\mathrm{nNOS}$ association with PSD-95 markedly increased on proestrus compared with diestrus (Fig. 4A) (nNOS/PSD-95 signal ratio, $0.346 \pm$ 0.045 in Di16h vs $0.543 \pm 0.046$ in Pro16h; $t$ test, $p=0.022 ; n=4$ independent experiments). These results suggest that the differential interaction between NR2B and nNOS in hypothalamic neurons during the estrous cycle is driven by changes in PSD-95/nNOS but not by NR2B/PSD-95.

\section{Estrogen induces physical}

approximation of $\mathrm{nNOS}$ and NR2B in neurons of the hypothalamic

\section{preoptic region}

At this stage of our results, we showed a natural fluctuation in the association of nNOS with NMDA receptors in preoptic region neurons, with an increased coupling during proestrus when plasma levels of estrogen are elevated (Smith et al., 1975), suggesting that the changes in protein interaction are attributable to changing levels of this ovarian steroid. Mimicking in OVX rats the preovulatory increase in plasma estrogen that occurs at proestrus, via subcutaneous injection of $17 \beta$-estradiol-3 benzoate-containing sesame oil (Kalra and McCann, 1973; Bouret et al., 2002b), resulted 2 d later in the increased coimmunoprecipitation of NR2B and nNOS from preoptic explants (Fig. 3D) (NR2B/nNOS signal ratio, $0.149 \pm 0.030$ in OVX vs $0.351 \pm 0.031$ in OVX $+\mathrm{E}$; $t$ test, $p=$ $0.009 ; n=4$ independent experiments), thus reproducing the $60 \mu \mathrm{m}$.


Figure 2. NMDA receptor NR2B subunit is expressed by N0-producing neurons in the preoptic region. Representative illustration of nNOS-expressing neurons (red) and NR2B subunit detection (green) by fluorescent immunocytochemistry in coronal brain sections from female rats showing progressively caudal sections of the preoptic region containing the vascular organ of the lamina terminalis (OV) (A), the MPO (B), and the MPN (C). V3, Third ventricle; ac, anterior commissure; oc, optic chiasm. Right, High magnifications of the areas delineated by rectangles. Arrowheads indicate double-labeled neurons expressing nNOS and NMDA receptor NR2B subunit. Arrows indicate NR2B single-labeled neurons. Scale bars: low magnification, $210 \mu \mathrm{m}$; high magnification,

Table 1. Percentages of the number of NR2B neurons immunoreactive for nNOS in diestrus and proestrus rats

\begin{tabular}{lllll}
\hline & AVPV & MEP0 & MP0 & MPN \\
\hline Diestrus & $13.9 \pm 3.4$ & $49.4 \pm 2.1$ & $32.5 \pm 2.6$ & $30.5 \pm 1.2$ \\
Proestrus & $12.6 \pm 1.2$ & $51.0 \pm 2.4$ & $30.8 \pm 1.1$ & $31.3 \pm 0.5$ \\
\hline
\end{tabular}

Four animals were used for counting in both stages of the estrous cycle; per animal, an average of $385 \pm 31$ NR2B-immunoreactive neurons was considered in the AVPV, $681 \pm 29$ in the MEPO, $422 \pm 15$ in the MPO, and $416 \pm 21$ in the MPN. 
A

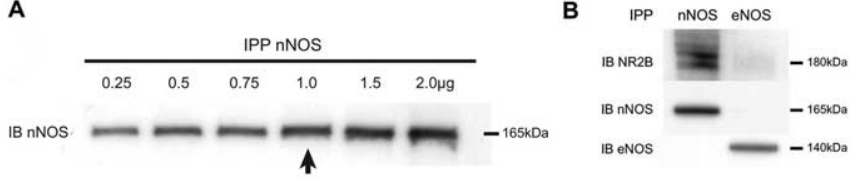

C

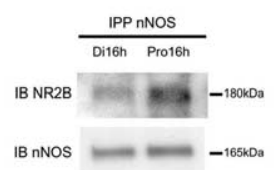

D

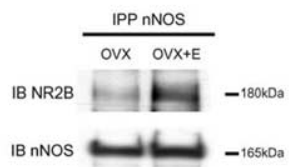

E

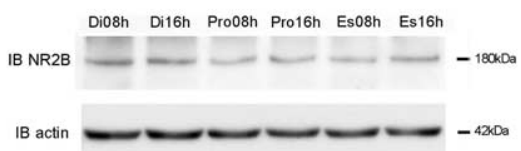

Figure 3. NMDA receptor NR2B subunit is highly physically associated with nNOS on the afternoon of proestrus. A, Protein $(2200 \mu \mathrm{m})$ collected from the rat preoptic region was immunoprecipitated with increasing concentrations of specific nNOS antibodies, electrophoresed to size fractionate the immunoprecipitated species, and immunoblotted with the same antibody. To quantify coprecipitated species in the subsequent experiments, $1 \mu \mathrm{g}$ of the nNOS antibody (arrow), which is a concentration that precipitates submaximal quantities of nNOS, was used to avoid any bias caused by potential variations in nNOS expression. $\boldsymbol{B}$, One microgram of the rabbit polyclonal antibody to $\mathrm{NNOS}$ coprecipitated NR2B from female rat preoptic region protein extracts, whereas $1 \mu \mathrm{g}$ of the rabbit polyclonal antibody to eNOS failed to do so. C, Increased association of nNOS with NR2B on the afternoon of proestrus (Pro16h) in the preoptic region of adult cycling female rats. $\boldsymbol{D}$, Estradiol (E) promotes nNOS/NR2B complex formation in the preoptic region of the female rat. A representative blot illustrating the increase in nNOS/NR2B coimmunoprecipitation in the $\mathrm{OVX}+\mathrm{E}$ female rat is shown. $\boldsymbol{E}$, Representative blot showing absence of changes in NR2B protein expression in the preoptic region of the hypothalamus during the estrous cycle of the adult female rat. The effective amount of protein loaded is represented by actin blot. Proteins were collected and processed as detailed in Figure 1C. IPP, Immunoprecipitated; IB, immunoblotted.
A

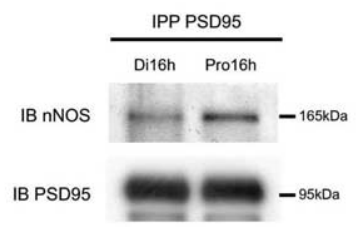

B

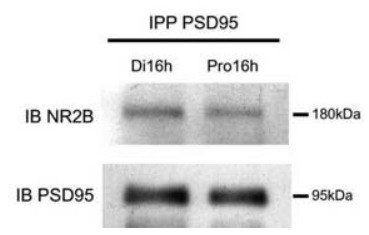

Figure 4. Differential NR2B/nNOS complex formation involves changes in physical association of PSD-95/nNOS but not NR2B/PSD-95. Immunoprecipitation (IPP) of preoptic region proteins with antibodies against PSD-95 results in the coprecipitation of nNOS $(\boldsymbol{A})$ and of NR2B $(\boldsymbol{B})$. Each observation derives from preoptic region tissue pooled from four rats. IB, Immunoblot.

increase in the NR2B/nNOS complex observed during a normal reproductive cycle on the afternoon of proestrus (Fig. 3C).

\section{In vivo PSD-95 knock-down by central administration of an antisense PSD-95 ODN impairs nNOS activity in preoptic neurons}

An increasing body of evidence suggests that a neuron-to-neuron signaling pathway involving $\mathrm{NO}$ regulates the activity of $\mathrm{GnRH}$ neurons within the preoptic region (Bonavera et al., 1993) and is required for normal central hormonal regulation of reproductive function (Gyurko et al., 2002). This communication pathway is triggered by glutamate through the activation of NMDA receptors (Bhat et al., 1998); this activation is necessary for the onset of the preovulatory GnRH surge that occurs on the afternoon of proestrus (Urbanski and Ojeda, 1990; Brann and Mahesh, 1991). To determine whether this system requires the scaffolding pro- tein PSD-95, we used antisense ODNs to inhibit PSD-95 expression (Sattler et al., 1999). Figure $5 A$ shows the inhibitory effectiveness of PSD-95 ODN treatment ( $5 \mu \mathrm{M}$ for $7 \mathrm{~d}$ ) that disrupts the physical approximation of PSD-95 with NR2B and PSD-95 expression in neurons of the rat preoptic region in vitro, an effect of the PSD-95 ODN not seen when the cells were treated with a scrambled ODN containing the same bases (data not shown) or the sense sequence (Fig. 5A). To determine whether PSD-95 expression may be efficiently impaired by these ODNs in vivo, adult female rats were infused with sense and antisense PSD-95 ODNs. The ODN was administered to the preoptic region (Fig. $5 B$ ) via a cannula connected to a subcutaneously implanted osmotic minipump. Immunofluorescent analysis of PSD-95 expression demonstrated that PSD-95 immunoreactivity was dramatically reduced at the tip of the implantation site in antisense PSD-95infused animals (Fig. 5D) (42 \pm 29 integrated density; $n=5)$ compared with sense PSD-95-treated rats (Fig. 5C) $(100 \pm 49$ integrated density; $n=5$; antisense PSD-95 vs sense PSD-95; $t$ test, $p=0.009$ ). As illustrated in Figure 5D, PSD-95 labeling in antisense-treated animals was extinguished at the injection site $\left(d^{\prime}\right)$ but increased slowly with a radial pattern and stained individual somata outside a $200-300 \mu \mathrm{m}$ radius $(d)$. Examination of sections from FITC-coupled antisense PSD-95 ODN-treated rats confirmed that the fluorescent ODN diffused from its infusion site as far as $200 \mu \mathrm{m}$, over a surface area encompassing a significant subset of nNOS-expressing cells (data not shown).

We next investigated whether hampering PSD-95 synthesis in the preoptic region alters NO formation in nNOS-expressing neurons. To provide microscopic visualization of NOS catalytic activity, we used immunohistofluorescence to localize L-citrulline (Eliasson et al., 1997; Keilhoff et al., 2000; Martinelli et al., 2002), which is formed stoichiometrically with NO (Garthwaite et al., 1988). In double-labeling experiments, all citrullinepositive neurons were also nNOS positive (Fig. 6). However, not all nNOS-positive neurons were immunoreactive for L-citrulline (average coexpression, $84 \pm 3 \% ; n=12 ; 2556 \pm 211 \mathrm{nNOS}$ neurons were counted per animal) (Fig. 6). Expectedly, intraperitoneal injection of L-NAME (50 mg/kg), a NOS inhibitor, $3.5 \mathrm{~h}$ before death abolished L-citrulline immunoreactivity in nNOS neurons (data not shown), thus validating the use of citrulline immunoreactivity as a monitor of NOS activity. In line with our results showing that NO production varies during the estrous cycle (Fig. 1), quantitative analysis showed that the number of citrulline-positive nNOS neurons was significantly higher in proestrus than in diestrus II in the preoptic region (average citrulline/nNOS coexpression: Di16h, $78 \pm 5 \%$; Pro16h, $90 \pm 2 \%$; $t$ test, $p=0.049 ; n=6$ per stage of the estrous cycle) (supplemental Fig. 1, available at www.jneurosci.org as supplemental material). To assess the importance of PSD-95 expression in the hypothalamic control of nNOS catalytic activity in vivo, the preoptic region of adult female rats were infused with the aforementioned PSD-95 ODN. Intracerebral application of the ODN resulted in a marked loss of L-citrulline immunoreactivity in most nNOSpositive neurons in the area surrounding the cannula implantation site (Fig. $6 B, D)(n=5$; one-way ANOVA, $p<0.001$; antisense PSD-95 vs all other groups), suggesting a loss of nNOS catalytic activity in those neurons. Interestingly, intracerebral L-NAME infusion extinguished all neuronal L-citrulline immunoreactivity in the preoptic region (Fig. $6 C, D)(n=4)$. Notably, this decrease in NO formation in the preoptic region was associated with inability to reach proestrus in all L-NAME-infused animals (Fig. 6C). In agreement with these data, animals treated with the NOS inhibitor that were allowed to survive longer 
showed a marked disruption of estrous cyclicity (supplemental Fig. 2, available at www.jneurosci.org as supplemental material) $(n=5$; $t$ test, $p=0.001$; L-NAME vs $\mathrm{NaCl})$.

\section{In vivo inhibition of PSD-95 synthesis} disrupts, in a reversible manner, female reproductive cyclicity

To further assess the physiological importance of hypothalamic PSD-95 scaffolding protein in the central control of mature reproductive function, adult female rats with regular estrous cycles were subjected to ODN infusion into the preoptic region at a rate of $0.1 \mathrm{nmol} / \mathrm{h}$ for $7 \mathrm{~d}$; control rats received infusions of the sense ODN. During the 2 weeks subsequent to the initiation of the treatment, the control animals had a normal $4 \mathrm{~d}$ estrous cycle $(n=6)$ (Fig. 7A). In contrast, animals infused with the antisense PSD-95 ODN exhibited weak to very pronounced disruption of estrous cyclicity on initiation of the treatment $(n=9)$ (Fig. 7A). Statistical analysis of the alterations in estrous cyclicity caused by antisense PSD-95 ODN delivery to the preoptic region showed a preponderance of days in diestrus and a concomitant reduction of days in proestrus and estrus (Fig. 7B) (one-way repeatedmeasures ANOVA, $p<0.05$, during infusion vs before infusion in the antisense PSD-95 ODN-treated group). Importantly, after the content of the pump was exhausted (i.e., after $7 \mathrm{~d}$ of infusion), all animals treated with antisense PSD-95 ODN recovered normal estrous cyclicity within a few days (Fig. 7B) (one-way repeated-measures ANOVA, $p<0.05$ ).

These results indicate that overall PSD-95 expression within the preoptic region and the changes in protein-protein interactions that occur via PSD-95 during fluctuating physiological conditions are both required for normal female reproductive cyclicity.

\section{Discussion}

The present results show that natural fluctuations of estrogen across the estrous cycle in adult female rat impacts nNOS activity, which accounts for most of the NO production in the CNS. The cellular bases of this action include physical approximation of nNOS with NMDA receptors via the scaffolding protein PSD-95. At proestrus, when circulating estrogens are at their highest, increased nNOS/PSD-95/NMDA receptor ternary complex formation is associated with parallel increases in NO production. Our findings suggest a role for estrogen in the modulation of interneuronal communication involving glutamatergic NMDA receptor activation of NO signaling. This pathway may be used to alternate coupling and uncoupling of glutamatergic fluxes for NO production during the reproductive cycle, thereby regulating NOergic neurotransmission and properties of synaptic transmission (Savchenko et al., 1997; Wang et al., 2005). In addition, because local disruption of PSD-95 expression in the preoptic region of the hypothalamus impairs estrous cyclicity as well as
B

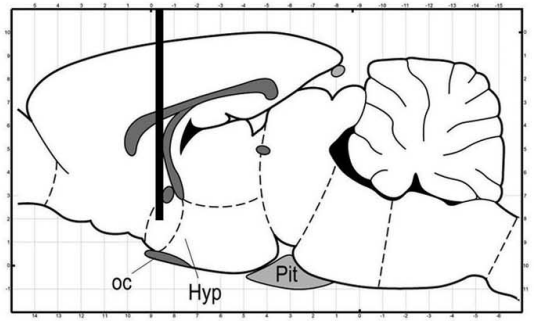

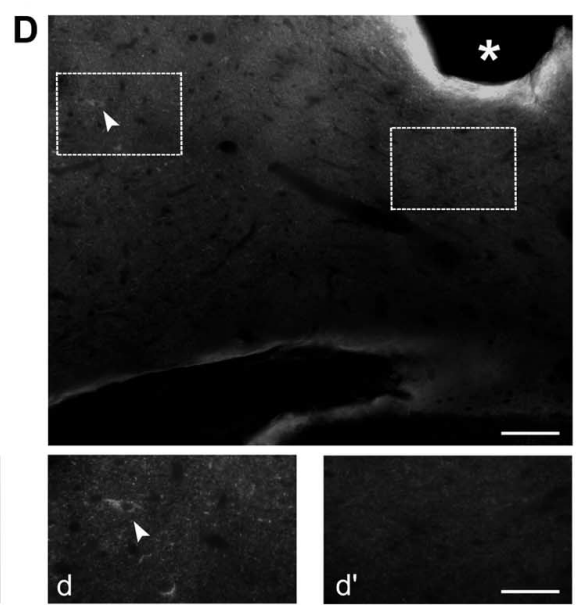

ression in neurons of the rat preoptic region. $A$, Selective decrease in PSD-95 expression and its association with NR2B in hypothalamic neurons treated with the antisense ODN to PSD-95 in vitro. Cells were treated with the antisense $\operatorname{ODN}(5 \mu \mathrm{M})$ or a sense sequence for $7 \mathrm{~d}$, and protein extracts were immunoprecipitated (IPP) with antibodies to PSD-95 and sequentially immunoblotted (IB) with NR2B and PSD-95 antibodies. The supernatan Coction diagram representing the stereotaxically implanted 28 gauge infusion cannula into the preoptic region of cycling female rats.

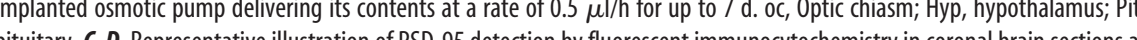
magnifications of the areas delineated by rectangles. The asterisk indicates the implanted cannula tip; arrowheads indicate

nNOS activity, our results demonstrate that dynamic changes in protein-protein interactions, including those involving nNOS and NMDA receptors, play a key role in the control of mature female reproductive function by the sexual brain.

The central control of reproduction operates through the timely activation of GnRH-containing neurons, the final pathway for neural control of ovulation, in the preoptic region (Ojeda and Terasawa, 2002). Activation of NMDA receptors, as well as estrogen itself, can stimulate $\mathrm{GnRH}$ neurons in vivo (for review, see Herbison, 1998; Mahesh and Brann, 2005). These effects may be attributable to interactions between sex steroids and glutamate-containing neural pathways because pharmacological blockade of either estrogen or glutamate NMDA receptors abolishes their stimulatory effects on $\mathrm{GnRH}$ /gonadotropin secretion (for review, see Herbison, 1998). Hormonal signals may influence glutamatergic neurotransmission in the brain by regulating, at least in part, protein complex assembly and organization at the postsynaptic density (Akama and McEwen, 2003), resulting in the elaboration of synaptic responses to glutamate with different properties (McEwen et al., 2001). In the preoptic region of the hypothalamus, most NMDA receptor-expressing neurons also contain estrogen receptor $\alpha$ (Chakraborty et al., 2003), which is not only localized to cell nuclei but also found in perikaryal cy- 
A
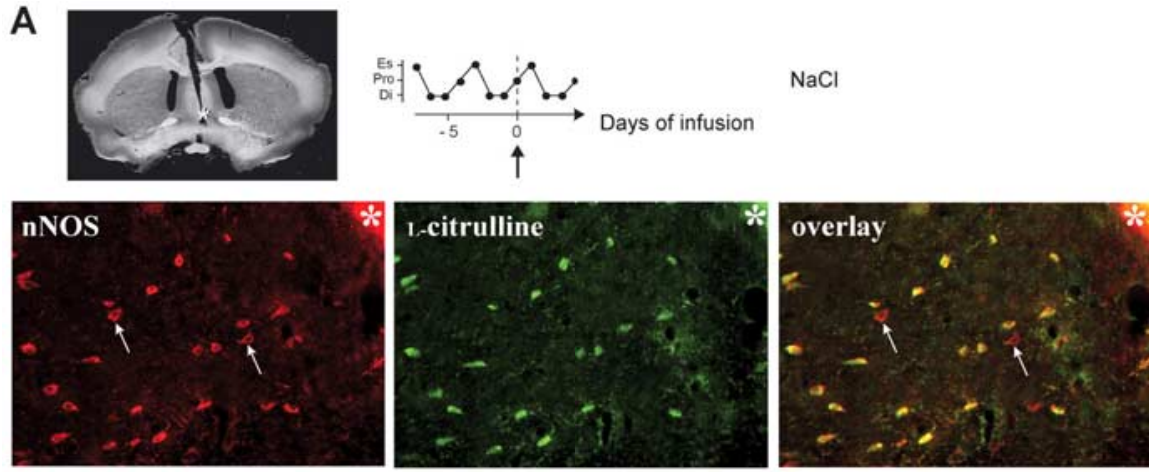

B
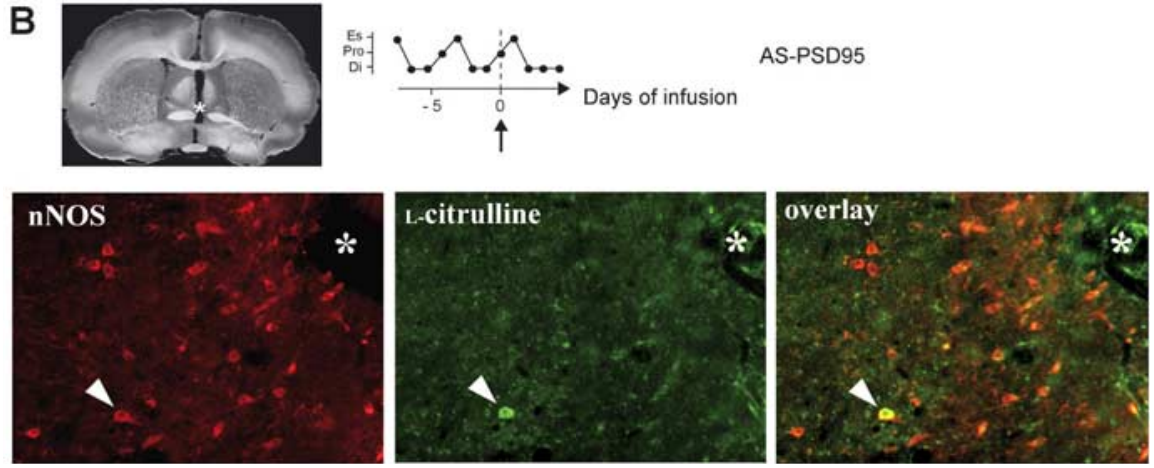

C
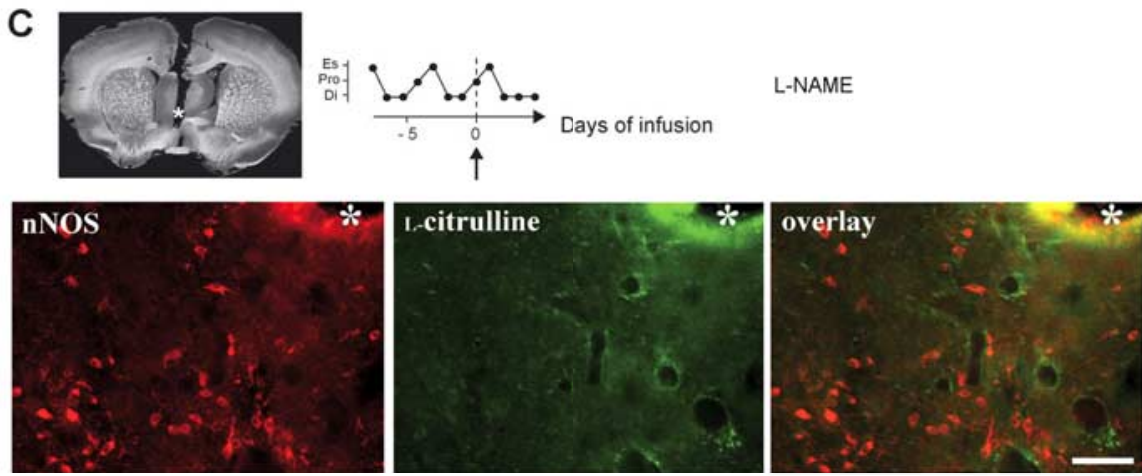

D

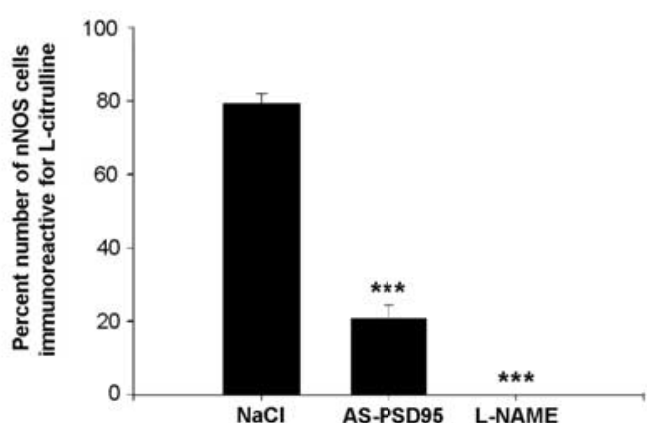

Figure 6. Central administration of an antisense PSD-95 (AS-PSD-95) ODN impairs NO formation in hypothalamic nNOS neurons. $\boldsymbol{A}-\boldsymbol{C}$, Antisense PSD-95 ODN (B), L-NAME (5 mm, a NOS inhibitor) (C), or vehicle $(0.9 \% \mathrm{NaCl})(\boldsymbol{A})$ was delivered into the preoptic region (top left) of adult female rats with regular estrous cycles as described in Figure 7; nNOS catalytic activity was evaluated in vivo by staining for L-citrulline (green), which is formed by nNOS (red) stoichiometrically with NO. In parallel, the effect of infusion on estrous cyclicity was monitored (top right). Infusion starts at day 0 (upward arrow), and animals were killed on day 4 , before the pump content was exhausted. A representative animal of each treatment group is shown. The asterisks indicate cannula implantation sites, arrows indicate nNOS single-labeled neurons, and arrowheads indicate a nNOS-expressing neuron immunolabeled for L-citrulline. Di, Diestrus; Pro, proestrus; Es, estrus. Scale bar, $70 \mu \mathrm{m}$. D, Bar graph illustrating the percentage number of nNOS neurons immunoreactive for $\mathrm{L}$-citrulline at the tip of the infusion site from animals treated with NaCl, AS-PSD-95 ODNs, or L-NAME $\left({ }^{* * *} p<0.001\right.$ compared with all other groups, one-way ANOVA; $n=4-5$ each). toplasm and dendrites (Blaustein, 1992; Blaustein et al., 1992). In fact, up to $90 \%$ of nNOS neurons of the preoptic region were shown to express estrogen receptor $\alpha$ (Scordalakes et al., 2002; Sato et al., 2005). Together with our results showing that virtually all nNOS neurons express NMDA receptor NR2B subunit, these studies suggest that most nNOS neurons in the preoptic region also contain estrogen receptors. In addition, estrogen receptor $\alpha$-expressing neurons of the AVPV and the MEPO, which contain a significant subset of hypothalamic nNOS neurons, are critical for estrogen positive feedback to GnRH neurons (Wintermantel et al., 2006). This recent finding raises the exciting possibility that nNOS neurons of the preoptic region may directly be involved in this process. Because GnRH neurons express neither nNOS (Herbison et al., 1996) nor estrogen receptor $\alpha$ (Herbison and Pape, 2001), estrogen-positive feedback on GnRH neurons must be indirect in nature. Within AVPV and MEPO neuronal populations afferent to and/or neighboring $\mathrm{GnRH}$ neurons increasing levels of circulating estrogen may promote NMDA receptor NR2B subunit/nNOS complex assembly, and thus potentiate NO secretion by coupling nNOS to its main stimulatory calcium influx pathway (Garthwaite et al., 1988; Bredt and Snyder, 1990). This idea is consistent with our data indicating that $\mathrm{NR} 2 \mathrm{~B} / \mathrm{nNOS}$ association in the preoptic region of the hypothalamus is increased by estrogen treatment of gonadectomized female rats, or at the onset of the preovulatory surge on proestrus, when NO production in this area is highest. Our results suggest that these findings are of functional relevance to the sexual brain because deletion of the catalytic heme-binding domain of nNOS centrally impairs reproductive function (Gyurko et al., 2002) and NO is suggested to mediate the NMDA receptor-dependent ovarian steroid-induced GnRH surge (Bonavera et al., 1993).

Like in other brain areas (Christopherson et al., 1999; Sattler et al., 1999; Aarts et al., 2002), our results suggest that NR2B/ nNOS complex formation in hypothalamic neurons involves the scaffolding protein PSD-95. PSD-95 is enriched in the postsynaptic density (Valtschanoff and Weinberg, 2001) and appears to be important for molecular organization of postsynaptic complex in neurons (Scannevin and Huganir, 2000). PSD-95 interacts with the intracellular $\mathrm{C}$ termini of NMDA receptors via the PDZ (PSD-95/ Discs large/zona occludens-1) domain 
(Kornau et al., 1995) but also with other transmembrane proteins such as Shaker $\mathrm{K}^{+}$channels (Kim et al., 1995) and erbB4 (Huang et al., 2000) and with intracellular signaling enzymes (Chen et al., 1998; Kim et al., 1998) including nNOS (Brenman et al., 1996). Our results show the existence of a distinct physical association between nNOS and PSD-95 at proestrus (when estrogen levels are highest) compared with a lower association between these two proteins at diestrus. This variation of nNOS association to PSD-95 correlates to the detected fluctuation of NR2B/nNOS complex formation. However, our data demonstrate that the estrous cycle has no effect on NR2B and PSD-95 association. These results thus suggest that estrogenstimulated NR2B/nNOS complex assembly is driven by changes in nNOS/PSD-95 interactions but not by NR2B/PSD-95. In addition, PSD-95 is shown to play a key role in regulating nNOS function within the hypothalamus. Our data indeed demonstrate that the temporary inhibition of PSD-95 expression targeted to the preoptic region resulted in a marked decrease in nNOS activity that was coupled to a reversible impairment of estrous cyclicity. It thus appears that hypothalamic PSD-95 synthesis is required for both NO production and adult reproductive function. Intriguingly, mice that express nNOS isoforms that are lacking the consensus domain required for their association with PSD-95 (Brenman et al., 1996) and mutant mice lacking PSD-95 (Migaud et al., 1998) are fertile. In contrast, our results show that temporary disruption of PSD-95 expression during adulthood in the neuroendocrine brain reversibly alters female reproductive function. This apparent discrepancy may stem from compensatory mechanisms that diminish the physiological manifestations of the biochemical dysfunctions in mutant mouse models that are unlikely to occur during a temporally restricted manipulation of gene expression.

Because PSD-95 is highly expressed throughout the hypothalamus, it is possible that the reproductive defects observed in antisense PSD-95 ODN-treated animals are the consequences of a generalized alteration in hypothalamic function instead of a specific defect affecting the interneuronal communication involving glutamatergic NMDA receptor activation of NO signaling controlling reproduction. However, the monitoring of key indicators of various other hypothalamic functions shows no alteration in antisense PSD-95 ODN-infused rats. Routine daily monitoring of body weight and inspection of water bottles showed that antisense PSD-95 ODN-treated rats have a growth curve and a water intake not different from that of sense PSD-95 ODN-infused controls, implicating a balanced energy homeostasis and no defects in the control of water balance (vasopressine secretion),



Central administration of an antisense PSD-95 ODN results in estrous cycle disruption in sexually mature rats. $\boldsymbol{A}$

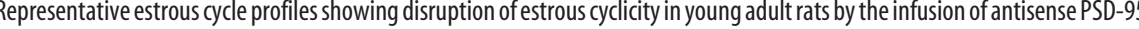
(AS-PSD-95) but not of sense PSD-95 (SE-PSD-95) 0DNs (0.2 $\mathrm{nmol} / \mu$ l each) into the hypothalamic preoptic region. Infusion arted at day 0 (upward arrow) and ended 7 d later (downward arrow), when the pump content was exhausted. Animals were analysis of the alterations in estrous cyclicity caused by antisense PSD-95-0DN infusion into the hypothalamic preoptic region. ${ }^{*} p<0.05$ compared with before and recovery for the same stage and the same treatment (repeated-measures ANOVA). Error bars indicate SEM. The number of independent observations per group is shown in parentheses. AS, antisense; SE, sense.

respectively. Again, it is possible that impairment of reproductive function that arises as a result to the temporary inhibition of PSD-95 gene expression is attributable to some disrupted pathways at the postsynaptic density besides the sole NMDA receptor/ nNOS. The use of peptides that selectively block the nNOS/ PSD-95 interaction, such as some used by Aarts et al. (2002), may represent an alternative method to further clarify the importance of the ternary complex formation in the central regulation of the adult reproductive function.

The mechanism by which estrogen promotes nNOS anchoring to the PSD-95/NMDA receptor complex remains unknown. Estrogen exhibits widespread effects throughout the brain, and its actions are intensively investigated, but very few studies have considered the relationship between estrogen and PSD-95. In 
vitro, estrogen upregulates the synthesis of PSD-95 via the Akt/ protein kinase B pathway (Akama and McEwen, 2003) and alters the shape of the hippocampal dendritic spine (Li et al., 2004) where PSD-95 is present in high amounts. Perhaps the nNOS association with PSD-95 is enhanced at synaptic sites in response to dynamic events at the postsynaptic density. One plausible mechanism for this would be that the estrogen signaling mediates the coalescence of cytoskeleton-tethered nNOS (Haraguchi et al., 2000) to PSD-95 through spine formation, which would require remodeling of the actin cytoskeleton (Hering and Sheng, 2001). Moreover, it has recently been shown that estradiol induces spine formation in neurons of the preoptic region through prostaglandin E2-mediated activation of glutamate AMPA-kainate receptors (Amateau and McCarthy, 2002). These studies suggest that such phenomenon could occur within the hypothalamus to modulate the nNOS subcellular localization.

Until now, increased coupling of nNOS to NMDA receptors by PSD-95 has been associated primarily with pathological conditions, particularly those involving excitotoxicity (Sattler et al., 1999; Aarts et al., 2002). Our results provide evidence that nNOS/ PSD-95/NMDA receptor ternary complex assemblies vary during fluctuating physiological conditions in discrete brain areas and suggest that such changes in protein-protein interactions are critical to fundamental physiological processes. In addition, our findings reveal a distinct role for estrogen in controlling nNOS/ PSD-95/NMDA receptor complex formation in the neuroendocrine brain and raise the intriguing possibility that such an effect of estrogen on protein-protein interactions may be broadly applied in the CNS to control nNOS activity.

\section{References}

Aarts M, Liu Y, Liu L, Besshoh S, Arundine M, Gurd JW, Wang YT, Salter MW, Tymianski M (2002) Treatment of ischemic brain damage by perturbing NMDA receptor- PSD-95 protein interactions. Science 298:846-850.

Akama KT, McEwen BS (2003) Estrogen stimulates postsynaptic density-95 rapid protein synthesis via the Akt/protein kinase B pathway. J Neurosci 23:2333-2339.

Altschul SF, Madden TL, Schaffer AA, Zhang J, Zhang Z, Miller W, Lipman DJ (1997) Gapped BLAST and PSI-BLAST: a new generation of protein database search programs. Nucleic Acids Res 25:3389-3402.

Amateau SK, McCarthy MM (2002) A novel mechanism of dendritic spine plasticity involving estradiol induction of prostaglandin-E2. J Neurosci 22:8586-8596.

Beauvillain JC, Tramu G (1980) Immunocytochemical demonstration of LH-RH, somatostatin, and ACTH-like peptide in osmium-postfixed, resin-embedded median eminence. J Histochem Cytochem 28:1014-1017.

Bhat GK, Mahesh VB, Ping L, Chorich L, Wiedmeier VT, Brann DW (1998) Opioid-glutamate-nitric oxide connection in the regulation of luteinizing hormone secretion in the rat. Endocrinology 139:955-960.

Blaustein JD (1992) Cytoplasmic estrogen receptors in rat brain: immunocytochemical evidence using three antibodies with distinct epitopes. Endocrinology 131:1336-1342.

Blaustein JD, Lehman MN, Turcotte JC, Greene G (1992) Estrogen receptors in dendrites and axon terminals in the guinea pig hypothalamus. Endocrinology 131:281-290.

Boehning D, Snyder SH (2003) Novel neural modulators. Annu Rev Neurosci 26:105-131.

Bonavera JJ, Sahu A, Kalra PS, Kalra SP (1993) Evidence that nitric oxide may mediate the ovarian steroid-induced luteinizing hormone surge: involvement of excitatory amino acids. Endocrinology 133:2481-2487.

Bouret S, Croix D, Mariot M, Loyens A, Prevot V, Jegou S, Vaudry H, Beauvillain JC, Mitchell V (2002a) Galanin modulates the activity of proopiomelanocortin neurons in the isolated mediobasal hypothalamus of the male rat. Neuroscience 112:475-485.

Bouret S, Prevot V, Takumi T, Beauvillain JC, Mitchell V (2002b) Regula- tion by gonadal steroids of the mRNA encoding for a type I receptor for TGF-beta in the female rat hypothalamus. Neuroendocrinology 76:1-7.

Brann DW, Mahesh VB (1991) Endogenous excitatory amino acid involvement in the preovulatory and steroid-induced surge of gonadotropins in the female rat. Endocrinology 128:1541-1547.

Bredt DS, Snyder SH (1990) Isolation of nitric oxide synthetase, a calmodulin-requiring enzyme. Proc Natl Acad Sci USA 87:682-685.

Bredt DS, Glatt CE, Hwang PM, Fotuhi M, Dawson TM, Snyder SH (1991) Nitric oxide synthase protein and mRNA are discretely localized in neuronal populations of the mammalian CNS together with NADPH diaphorase. Neuron 7:615-624.

Brenman JE, Chao DS, Gee SH, McGee AW, Craven SE, Santillano DR, Wu Z, Huang F, Xia H, Peters MF, Froehner SC, Bredt DS (1996) Interaction of nitric oxide synthase with the postsynaptic density protein PSD-95 and alpha1-syntrophin mediated by PDZ domains. Cell 84:757-767.

Burette A, Zabel U, Weinberg RJ, Schmidt HH, Valtschanoff JG (2002) Synaptic localization of nitric oxide synthase and soluble guanylyl cyclase in the hippocampus. J Neurosci 22:8961-8970.

Calizo LH, Flanagan-Cato LM (2000) Estrogen selectively regulates spine density within the dendritic arbor of rat ventromedial hypothalamic neurons. J Neurosci 20:1589-1596.

Chakraborty TR, Ng L, Gore AC (2003) Colocalization and hormone regulation of estrogen receptor alpha and N-methyl-D-aspartate receptor in the hypothalamus of female rats. Endocrinology 144:299-305.

Chen HJ, Rojas-Soto M, Oguni A, Kennedy MB (1998) A synaptic RasGTPase activating protein (p135 SynGAP) inhibited by CaM kinase II. Neuron 20:895-904.

Christopherson KS, Hillier BJ, Lim WA, Bredt DS (1999) PSD-95 assembles a ternary complex with the N-methyl-D-aspartic acid receptor and a bivalent neuronal NO synthase PDZ domain. J Biol Chem 274:27467-27473.

Clancy B, Cauller LJ (1998) Reduction of background autofluorescence in brain sections following immersion in sodium borohydride. J Neurosci Methods 83:97-102.

Czaja K, Ritter RC, Burns GA (2006) N-methyl-D-aspartate receptor subunit phenotypes of vagal afferent neurons in nodose ganglia of the rat. J Comp Neurol 496:877-885.

El-Husseini AE, Craven SE, Chetkovich DM, Firestein BL, Schnell E, Aoki C, Bredt DS (2000) Dual palmitoylation of PSD-95 mediates its vesiculotubular sorting, postsynaptic targeting, and ion channel clustering. J Cell Biol 148:159-172.

Eliasson MJ, Blackshaw S, Schell MJ, Snyder SH (1997) Neuronal nitric oxide synthase alternatively spliced forms: prominent functional localizations in the brain. Proc Natl Acad Sci USA 94:3396-3401.

Garthwaite J, Charles SL, Chess-Williams R (1988) Endothelium-derived relaxing factor release on activation of NMDA receptors suggests role as intercellular messenger in the brain. Nature 336:385-388.

Gould E, Woolley CS, Frankfurt M, McEwen BS (1990) Gonadal steroids regulate dendritic spine density in hippocampal pyramidal cells in adulthood. J Neurosci 10:1286-1291.

Gyurko R, Leupen S, Huang PL (2002) Deletion of exon 6 of the neuronal nitric oxide synthase gene in mice results in hypogonadism and infertility. Endocrinology 143:2767-2774.

Haraguchi K, Satoh K, Yanai H, Hamada F, Kawabuchi M, Akiyama T (2000) The hDLG-associated protein DAP interacts with dynein light chain and neuronal nitric oxide synthase. Genes Cells 5:905-911.

Herbison AE (1998) Multimodal influence of estrogen upon gonadotropinreleasing hormone neurons. Endocr Rev 19:302-330.

Herbison AE, Pape JR (2001) New evidence for estrogen receptors in gonadotropin-releasing hormone neurons. Front Neuroendocrinol 22:292-308.

Herbison AE, Simonian SX, Norris PJ, Emson PC (1996) Relationship of neuronal nitric oxide synthase immunoreactivity to GnRH neurons in the ovariectomized and intact female rat. J Neuroendocrinol 8:73-82.

Hering H, Sheng M (2001) Dendritic spines: structure, dynamics and regulation. Nat Rev Neurosci 2:880-888.

Huang YZ, Won S, Ali DW, Wang Q, Tanowitz M, Du QS, Pelkey KA, Yang DJ, Xiong WC, Salter MW, Mei L (2000) Regulation of neuregulin signaling by PSD-95 interacting with ErbB4 at CNS synapses. Neuron 26:443-455.

Ishii H, Shibuya K, Ohta Y, Mukai H, Uchino S, Takata N, Rose JA, Kawato S (2006) Enhancement of nitric oxide production by association of nitric oxide synthase with $\mathrm{N}$-methyl-D-aspartate receptors via postsynaptic 
density 95 in genetically engineered Chinese hamster ovary cells: real-time fluorescence imaging using nitric oxide sensitive dye. J Neurochem 96:1531-1539.

Kalra P, McCann SM (1973) Involvement of catecholamines in feedback mechanisms. Prog Brain Res 39:185-198.

Keilhoff G, Reiser M, Stanarius A, Aoki E, Wolf G (2000) Citrulline immunohistochemistry for demonstration of NOS activity in vivo and in vitro. Nitric Oxide 4:343-353.

Kim E, Niethammer M, Rothschild A, Jan YN, Sheng M (1995) Clustering of Shaker-type $\mathrm{K}+$ channels by interaction with a family of membraneassociated guanylate kinases. Nature 378:85-88.

Kim JH, Liao D, Lau LF, Huganir RL (1998) SynGAP: a synaptic RasGAP that associates with the PSD-95/SAP90 protein family. Neuron 20:683-691.

Knauf C, Prevot V, Stefano GB, Mortreux G, Beauvillain JC, Croix D (2001) Evidence for a spontaneous nitric oxide release from the rat median eminence: influence on gonadotropin-releasing hormone release. Endocrinology 142:2343-2350.

Kornau HC, Schenker LT, Kennedy MB, Seeburg PH (1995) Domain interaction between NMDA receptor subunits and the postsynaptic density protein PSD-95. Science 269:1737-1740.

Lemoine S, Leroy D, Warembourg M (2005) Progesterone receptor and dopamine synthesizing enzymes in hypothalamic neurons of the guinea pig: an immunohistochemical triple-label analysis. J Chem Neuroanat 29:13-20.

Li C, Brake WG, Romeo RD, Dunlop JC, Gordon M, Buzescu R, Magarinos AM, Allen PB, Greengard P, Luine V, McEwen BS (2004) Estrogen alters hippocampal dendritic spine shape and enhances synaptic protein immunoreactivity and spatial memory in female mice. Proc Natl Acad Sci USA 101:2185-2190.

Maggi A, Ciana P, Belcredito S, Vegeto E (2004) Estrogens in the nervous system: mechanisms and nonreproductive functions. Annu Rev Physiol 66:291-313.

Mahesh VB, Brann DW (2005) Regulatory role of excitatory amino acids in reproduction. Endocrine 28:271-280.

Martinelli GP, Friedrich Jr VL, Holstein GR (2002) L-citrulline immunostaining identifies nitric oxide production sites within neurons. Neuroscience 114:111-122.

McCann SM, Haens G, Mastronardi C, Walczewska A, Karanth S, Rettori V, Yu WH (2003) The role of nitric oxide (NO) in control of LHRH release that mediates gonadotropin release and sexual behavior. Curr Pharm Des 9:381-390.

McEwen B, Akama K, Alves S, Brake WG, Bulloch K, Lee S, Li C, Yuen G, Milner TA (2001) Tracking the estrogen receptor in neurons: implications for estrogen-induced synapse formation. Proc Natl Acad Sci USA 98:7093-7100.

Migaud M, Charlesworth P, Dempster M, Webster LC, Watabe AM, Makhinson M, He Y, Ramsay MF, Morris RG, Morrison JH, O'Dell TJ, Grant SG (1998) Enhanced long-term potentiation and impaired learning in mice with mutant postsynaptic density-95 protein. Nature 396:433-439.

Odum J, Tinwell H, Jones K, Van Miller JP, Joiner RL, Tobin G, Kawasaki H, Deghenghi R, Ashby J (2001) Effect of rodent diets on the sexual development of the rat. Toxicol Sci 61:115-127.

Ojeda SR, Terasawa E (2002) Neuroendocrine regulation of puberty (Pfaff D, Arnold A, Etgen A, Fahrbach S, Moss R, Rubin R, eds), pp 589-659. New York: Elsevier.

Okamura H, Yokosuka M, Hayashi S (1994) Estrogenic induction of NADPH-diaphorase activity in the preoptic neurons containing estrogen receptor immunoreactivity in the female rat. J Neuroendocrinol 6:597-601.

Prast H, Philippu A (2001) Nitric oxide as modulator of neuronal function. Prog Neurobiol 64:51-68.
Prevot V, Dutoit S, Croix D, Tramu G, Beauvillain JC (1998) Semiquantitative ultrastructural analysis of the localization and neuropeptide content of gonadotropin releasing hormone nerve terminals in the median eminence throughout the estrous cycle of the rat. Neuroscience 84:177-191.

Prevot V, Croix D, Rialas CM, Poulain P, Fricchione GL, Stefano GB, Beauvillain JC (1999) Estradiol coupling to endothelial nitric oxide stimulates gonadotropin-releasing hormone release from rat median eminence via a membrane receptor. Endocrinology 140:652-659.

Pu S, Xu B, Kalra SP, Kalra PS (1996) Evidence that gonadal steroids modulate nitric oxide efflux in the medial preoptic area: effects of N-methyl$\mathrm{D}$-aspartate and correlation with luteinizing hormone secretion. Endocrinology 137:1949-1955.

Pu S, Kalra PS, Kalra SP (1998) Ovarian steroid-independent diurnal rhythm in cyclic GMP/nitric oxide efflux in the medial preoptic area: possible role in preovulatory and ovarian steroid-induced LH surge. J Neuroendocrinol 10:617-625.

Sato S, Braham CS, Putnam SK, Hull EM (2005) Neuronal nitric oxide synthase and gonadal steroid interaction in the MPOA of male rats: colocalization and testosterone-induced restoration of copulation and nNOS-immunoreactivity. Brain Res 1043:205-213.

Sattler R, Xiong Z, Lu WY, Hafner M, MacDonald JF, Tymianski M (1999) Specific coupling of NMDA receptor activation to nitric oxide neurotoxicity by PSD-95 protein. Science 284:1845-1848.

Savchenko A, Barnes S, Kramer RH (1997) Cyclic-nucleotide-gated channels mediate synaptic feedback by nitric oxide. Nature 390:694-698.

Scannevin RH, Huganir RL (2000) Postsynaptic organization and regulation of excitatory synapses. Nat Rev Neurosci 1:133-141.

Scordalakes EM, Shetty SJ, Rissman EF (2002) Roles of estrogen receptor alpha and androgen receptor in the regulation of neuronal nitric oxide synthase. J Comp Neurol 453:336-344.

Simerly RB (2005) Wired on hormones: endocrine regulation of hypothalamic development. Curr Opin Neurobiol 15:81-85.

Smith MS, Freeman ME, Neill JD (1975) The control of progesterone secretion during the estrous cycle and early pseudopregnancy in the rat: prolactin, gonadotropin and steroid levels associated with rescue of the corpus luteum of pseudopregnancy. Endocrinology 96:219-226.

Swanson LW (1996) Structure of the rat brain. Amsterdam: Elsevier Science Publishers.

Urbanski HF, Ojeda SR (1990) A role for N-methyl-D-aspartate (NMDA) receptors in the control of $\mathrm{LH}$ secretion and initiation of female puberty. Endocrinology 126:1774-1776.

Valtschanoff JG, Weinberg RJ (2001) Laminar organization of the NMDA receptor complex within the postsynaptic density. J Neurosci 21:1211-1217.

Wang HG, Lu FM, Jin I, Udo H, Kandel ER, de Vente J, Walter U, Lohmann SM, Hawkins RD, Antonova I (2005) Presynaptic and postsynaptic roles of NO, cGK, and RhoA in long-lasting potentiation and aggregation of synaptic proteins. Neuron 45:389-403.

Weiner CP, Lizasoain I, Baylis SA, Knowles RG, Charles IG, Moncada S (1994) Induction of calcium-dependent nitric oxide synthases by sex hormones. Proc Natl Acad Sci USA 91:5212-5216.

Wintermantel TM, Campbell RE, Porteous R, Bock D, Grone HJ, Todman MG, Korach KS, Greiner E, Perez CA, Schutz G, Herbison AE (2006) Definition of estrogen receptor pathway critical for estrogen positive feedback to gonadotropin-releasing hormone neurons and fertility. Neuron 52:271-280.

Woolley CS, McEwen BS (1992) Estradiol mediates fluctuation in hippocampal synapse density during the estrous cycle in the adult rat. J Neurosci 12:2549-2554.

Zar JH (1984) Biostatistical analysis. Englewood Cliffs, NJ: Prentice Hall. 